ScIDice

\section{Evaluation of Subcutaneous Immunotherapy in Asthmatics to Dermatophagoides Siboney and Dermatophagoides Pteronyssinus}

International Journal of Clinical \& Medical Allergy (IJCMA) ISSN 2332-2799

Raúl Lázaro Castro-Almarales, $\mathrm{MD}^{1 *}$, Mercedes Ronquillo-Díaz, $\mathrm{MD}^{2}$, Mirta Álvarez-Castelló, MD, $\mathrm{PhD}^{3}$, José Rodríguez-Canosa, MD4, Mayda González-León ${ }^{5}$, Irene Enríquez-Domínguez, MD ${ }^{6}$, Bárbara Ivonne Navarro-Viltre, MD ${ }^{7}$, Maytee Mateo-Morejón, BSc ${ }^{8}$, Yunia Oliva-Díaz, BSc ${ }^{9}$, Wendy Ramírez-González, BSc ${ }^{10}$, Alexis Labrada-Rosado, $\mathrm{PhD}^{11}$

\footnotetext{
${ }^{1}$ Second Degree Specialist in Allergy, Auxiliary Professor and Researcher.Centro Nacional de Biopreparados, Bejucal, Mayabeque, Cuba.UniversityHospital "General Calixto García", Allergy and Immunology Service, Havana, Cuba.

${ }^{2}$ Second Degree Specialist in Allergy, Auxiliary Professor; University Hospital “General Calixto García”, Allergy and Immunology Service, Havana, Cuba.

${ }^{3}$ Second Degree Specialist in Allergy, Auxiliary Professor and Researcher; University Hospital "General Calixto García", Allergy and Immunology Service, Havana, Cuba.

${ }^{4}$ Second Degree Specialist in Allergy, Auxiliary Professor; UniversityHospital “General Calixto García”, Allergy and Immunology Service, Havana, Cuba.

${ }^{5}$ Second Degree Specialist in Integral General Medicine, Teaching Polyclinic "Pedro Fonseca Álvarez”, La Lisa, Havana, Cuba.

${ }^{6}$ First Degree Specialist in Allergy and Integral General Medicine, University Hospital "General Calixto García”, Allergy and Immunology Service, Havana, Cuba.

${ }^{7}$ First Degree Specialist in Allergy, Master in Immunology, Teaching Polyclinic "Capdevila", Boyeros, Havana, Cuba.

${ }^{8}$ Centro Nacional de Biopreparados, Allergens Department, Bejucal, Mayabeque, Cuba.

${ }^{9}$ Centro Nacional de Biopreparados, Allergens Department, Bejucal, Mayabeque, Cuba.

${ }^{10}$ Centro Nacional de Biopreparados, Allergens Department, Bejucal, Mayabeque, Cuba.

${ }^{11}$ Director of Research and Development. Centro Nacional de Biopreparados, Bejucal, Mayabeque, Cuba.
}

\section{Introduction}

Prevalence of allergic diseases such as allergic rhinitis and asthma is increasing to epidemic proportions in the world. [1-3] In Latin America, asthma prevalence is higher in tropical regions. [2-4] Particularly, in Cuba, asthma affects from $8.5 \%$ to $10 \%$ of adults and up to $17.8 \%$ of children, [5-8] and it is associated with high morbidity and profound social and economic impact, including reduced quality of life of patients, lower productivity and increase of indirect and direct costs. [9-10]

Increase of prevalence of allergic asthma is commonly associated with changes in lifestyle and environment. Particularly, allergic asthma is strongly linked to $\operatorname{IgE}$ sensitization to House Dust Mites(HDM).[2, 3, 11, 12] Epidemiologic studies performed in Cuba have reported that the more relevant HDMspecies are Dermatophagoides pteronyssinus (Dp), Dermatophagoides siboney (Ds) and Blomiatropicalis (Bt).13-16D. siboney is a tropical species described first in Cuba and found also in the Caribbean [11] [12], phylogenetically very close to $\mathrm{D}$. farinae, which is absent in
Cuba. The allergenic relevance of $\mathrm{D}$. siboney and its strong association with asthma in Cuba has been reported previously. [13-15] D. siboney shares extensive cross-reactivity with D. farina and D. pteronyssinus, which is also common in Cuba.[15]

Management of allergic asthma is based on pharmacological symptomatic treatment, allergen avoidance and allergen-specific immunotherapy.[17-20] Allergen-specific immunotherapy (AIT) is presently acknowledged as a biological response modifier, inducing immunological tolerance towards the allergen.

It is the only available treatment able to influence the natural course of allergic disease. Extensive clinical evidence supports the efficacy of AIT.[21] In addition, this etiological therapeutic approach can be used also in a preventive setting, avoiding development of new sensitizations and the aggravation of the disease.

The clinical effect of AIT is based on modulation of the Th1/ Th2 balance of the allergen-specific immune response, inducing also $\mathrm{T}$ regulatory cells and IgG4 blocking antibodies.[17-20]

*Corresponding Author

Raúl Lázaro Castro-Almarales, MD

National Center of Bioproducts, Division of Research and Development, Clinical Trials Group. Carretera Beltrán km 11/2, Bejucal, Zip postal 32600, Mavabeque, Cuba. Tel/Fax: +53-47682441

Email ID: rcastro@biocen.cu

Received: October 22, 2021

Accepted: January 24, 2022

Published: January 28, 2022

Citation: Raúl Lázaro Castro-Almarales, MD, Mercedes Ronquillo-Díaz, MD, Mirta Álvarez-Castelló, MD, PhD, José Rodríguez-Canosa, MD, Mayda González-León, Irene Enríquez-Domínguez, MD, et al., Evaluation of Subcutaneous Immunotherapy in Asthmatics to Dermatophagoides Siboney and Dermatophagoides Pteronyssinus. Int J Clin Med Allergy. 2022;07(01):73-80. doi: http://dx.doi.org/10.19070/2332-2799-2200014

Copyright: Raúl Lázaro Castro-Almarales, MD $^{\circ}$ 2022. This is an open-access article distributed under the terms of the Creative Commons Attribution License, which permits unrestricted use, distribution and reproduction in any medium, provided the original author and source are credited. 
Safety concerns about injection AIT are related to the risks of anaphylactic reactions during treatment. In this regard, the standardization of the allergen products, in terms of allergenic activity, is very relevant for the accurate control of the administered doses. $[17,18,20,22]$

AIT using HDM allergens, is regarded an effective treatment for mild to moderate asthma in sensitized patients.[21, 22] A key aspect is the proper selection of the allergens and the assessment of its relevance to the disease. Both, D. pteronyssinus and D. siboney are regarded as important allergen sources and sensitizers for $\mathrm{Cu}$ ban asthmatics. $[5,7,13,16]$ Therefore, the aim of this work was to assess the efficacy and safety of standardized allergen extracts of Dermatophagoides pteronyssinus and Dermatophagoides siboney by subcutaneous route in allergic asthmatic adults sensitized to these mite species.

\section{Methods}

\section{Study design}

Two separate clinical trials, for each allergen product, Dp and Ds, were conducted simultaneously; both with the same design: Phase II (therapeutic effect), double-blind, placebo-controlled, ramdomized trials, in 40 adult asthmatic patients each, with mild to moderate persistent asthma. Half of the patients in each trial received active treatment and the other half placebo. Both trials were conducted at the Allergy and Immunology Service of the "General Calixto García" University Hospital (Code in the Cuban Public Registry of Clinical Trials: RPCEC00000027 and RPCEC00000028).[23] The studies were designed and conducted according with the international guidelines for Good Clinical Practice and were approved by the Research Ethics Committee of the clinical site and the Cuban regulatory authority (CECMED).

\section{Treatment}

Allergen injections were administered by subcutaneous route in a dose escalation scheme, first, aninduction phase with weekly injections during the first 13 weeks, followed by a maintenance phase ofmonthly injections up to 12 months (Table 1). The 100\% of included patients completing 12 months of AIT. Standardized allergen extracts VALERGEN-DP (D. pteronyssinus) and VALERGEN-DS (D. siboney), developed and manufactured by BIOCEN (Bejucal, Cuba) were used. Both products are licensed in Cuba as medicines. The standardization is expressed in Biological Units (BU) according to the definition of Nordic Guidelines for the Registration of Allergen Products. [24] The maintenance dose was $6000 \mathrm{BU}$, which is equivalent to $12 \mu \mathrm{g}$ of the major allergen Der p 1 or $24 \mu \mathrm{g}$ of Der s 1, respectively.[25]

Extracts are available as freeze-dried products, which are reconstituted in an aqueous PBS albumin diluent. Both, the active and control group, received concomitant symptomatic treatment comprisingantihistamines, bronchodilators, $\beta 2$-agonists and oral steroids, as prescribed by blinded physicians.

\section{Participants}

The study involved men and women aged 18 to 45 years with clinical diagnosis of mild to moderate persistent asthma diagnosed according to Global Initiative for Asthma (GINA) guidelines, [26] possiblyincluding concomitant manifestations of rhinitis, atopic dermatitis and/or conjunctivitis. Diagnosis ofallergic asthma was performed by an expert physician and took into account individual patient history,physical examination and response upon bronchodilator administration, with a minimum of $12 \%$ Peak.

Expiratory Flow increase. Patient's allergic status was supported by a positive skin prick test to $\mathrm{D}$. pteronyssinus or $\mathrm{D}$. siboney allergen extracts (Centro Nacional de Biopreparados (BIOCEN), Cuba, $20000 \mathrm{BU} / \mathrm{mL}$ ) and clinical assessment consistent with allergic respiratory symptoms (cough, wheezing, chest tightness and dyspnea) upon exposure to house dust. The skin test was considered positive if the wheal diameter was greater or equal to $3 \mathrm{~mm}$. Since strict monosensitization in this case is practically impossible due to the high degree of cross-reactivity between both mite species, patients with predominant sensitization to one of the two species were selected, i.e. with a reaction size larger than $2 \mathrm{~mm}$, with respect to the other mite species. In addition to D. siboney and D. pteronyssinus, reactivity to Blomiatropicalis was also tested. Patients were excluded from the trial if they had been treated with allergen immunotherapy in the last two years, or if they had had severe intermittent or persistent asthma or received immunostimulant or immunosuppressive treatment one year prior to the study.

\section{Outcomes}

The therapeutic effect was measured through symptom and medication scores, and the combination of both as the main endpoint. In addition, lung function, and skin reactivity relative to histamine (Ch10) were used also as secondary outcomes. Symptom and Medication (SM) scores were collected using a form filled by the patient with a 4 level scale with the following values: $0=$ absent, $1=$ mild, $2=$ moderate, $3=$ severe, for each symptom manifestation (cough, wheezing, chest tightness and dyspnea). In addition, Medication Score measured the frequency of drug intake. Each time a drug was consumed the score was incremented by 1 point, except oral steroids that worth 2 points. At the end of the month, all points were summed. [27, 28] For the semi annual partial evaluations (at months 6 and 12) the values of the last two months were averaged: 5-6, and 11-12 months, respectively. Baseline pretreatment value was established measuring SM scores during one month. For comparing with published meta-analysis the Standard Mean Difference (SMD) was calculated (i.e. difference between Active and Placebo, divided by the standard error) according to Cochrane methodology.[29]

Allergen specific reactivity was assessed by Skin Prick Test (SPT) to Dp, Ds and Bt allergen extractsat $20000 \mathrm{BU} / \mathrm{mL}$. Stainless steel lancets with tips of $1 \mathrm{~mm}$ (ALK, Denmark) were used according toDreborg. [30] Histamine $\mathrm{HCl} 10 \mathrm{mg} / \mathrm{mL}$ was used as a positive control, and as a negative control, PBS. Inorder to record the test results, a line was drawn around the wheal and transferred to a transparent adhesive tape, which was taped on to the data recording book. The largest and the orthogonal diameters were measured on the wheal drawing, and the mean diameter was calculated. Furthermore, the mean diameter (d) between the two arms was calculated. The test was considered valid if the difference between both arms wheals was less than $2 \mathrm{~mm}$ for wheals between 3 and $6 \mathrm{~mm}$, or less than $3 \mathrm{~mm}$ for larger wheals; besides being positive for Histamine (positive control) and negative for 
the diluent solution (negative control). The test was considered positive for $\mathrm{d} \geq 3 \mathrm{~mm}$. Wheal area was calculated from the mean diameter (d) according to the expression: $\mathrm{A}=\pi(\mathrm{d} 2 / 4)$. Allergen specific reactivity was calculated relative to the Histamine $10 \mathrm{mg} /$ $\mathrm{mL}$, using this expression:[30]

$\mathrm{Ch} 10=(\mathrm{Aa} / \mathrm{Ah}) 2.5$

(where Aa: allergen wheal area; Ah: histamine wheal area).

Pulmonary function was measured through Peak Expiratory Flow (PEF) with the use of a portable PEF meter (Ferraris, UK). This measurement was performed daily by the patient at home, whereas daily PEF variability was calculated by the physician. $[31,32]$

A secondary dichotomical variable was used to assess the overall clinical improvement (OCI) of eachpatient, with two levels: "better" and "not better". The "better" value was assigned when the symptom/medication score was reduced below 60\%, 27 with respect to the baseline and the skin reactivity (Ch10) and lung function category did not worsen with respect to the beginning of the treatment.

\section{Safety assessment}

Adverse reactions were recorded and classified as local or systemic, or immediate or delayed.[33] Local reactions were assessed by erythema diameter. Local immediate reactions with a diameter of less than $5 \mathrm{~cm}$ and delayed reactions of less than $10 \mathrm{~cm}$ were considered mild. Systemic reactions were graded in accordance with the World Allergy Organization.[34]

\section{Statistical methods}

The statistical package GlaxoWellcome C4-SDP was used for the calculation of the sample size and randomization to intervention groups. Thus, the sample size needed to obtain a relevant preset minimum difference, between two proportions from two groups P1 (Placebo) and P2 (Active), was calculated. The following input data were used: P2-P1 $=53 \% ; \alpha=0.05 ; \beta=0.10$. Output: required subjects $n=14$. Simple random assignment was used with equal probability to each study arm: placebo or active. For data processing and hypothesis testing the statistical package STATISTICA v.5.0 (Statsoft, USA) was used. Outcome data was analyzed in a blinded manner at the two planned evaluative points: 6 and 12 months, with all patients, without exclusions. Testing to normality of variables was assessed by the Kolmogorov-Smirnov and Shapiro-Wilks tests. Non-parametric methods were applied to all variables (except height, weight and skin reactivity, Ch10). Thus, the central values were expressed by the median and its 95\% Confidence Interval and comparisons between the Active and Placebo groups were performed using the Mann-Whitney U test. Comparisons within each group with respect to pre-treatment values were performed using the Wilconxon test for paired samples. For Ch10, a log transformation was performed and, after verification of its adjustment to normality. The following parametric methods were used for height, weight and Ch10: t-test for the comparison between groups; and t-test with paired data for the comparison within the same group with respect to the baseline values. For comparison of frequencies between groups the Pearson's chi-squared test $(\chi 2)$ was used. Finally, the correlation analysis between the variables was performed using from the non- parametric Spearman correlation coefficient.

\section{Results}

Of 393 patients evaluated with asthma symptoms, presumably related to indoor allergens, and whoexpressed their consent to participate in the trial, only 80 patients $(20.4 \%$ ) were selected (Fig. 1 ). The major limitation in this sense was the requirement of the preponderant skin reactivity towards theinvestigated allergens (Dp and Ds). Roughly $72 \%$ of patients showed polysensitization to the three evaluated species Dp, Ds and Bt, and only 8.6\% did not show a positive response to any of them. In addition to asthma, most patients also showed rhinitis symptoms: for the Ds trial 30 out of 40 included patients $(75 \%)$, and for the Dp trial 34 out of 40 patients $(85 \%)$.

As expected by design, the Active and Placebo groups were comparable in terms of demographic and clinical variables in both trials with no statistical differences ( $\mathrm{p}>0.05)$ (Table 2). All 80 included patients completed the trials. No dropouts were recorded and no patient developed criteria for leaving the study.

Regarding outcomes, clinical symptoms significantly decreased down to $36.5 \%$ (95\% CI: $28-36 \%$ ) and medication, down to $23 \%$ (95\% CI: $18-28 \%$ ) as compared to placebo values, as an average of the two trials $(\mathrm{p}<0.001)$. The combined symptom/medication score significantly decreased down to $39 \%$ for Dp and $34 \%$ for Ds. The difference between the Active and Placebo groups was significant $(\mathrm{p}<0.05)$ even at 6 months, and more pronounced at 12 months $(p<0.001)$. The decreasing effect was also significant $(p<0.01)$ as compared to the beginning of the treatment within the active group (Fig 2). As for lung function in the active group, an apparent, although non-significant, slight increase in PEF value was noted: $2.3 \%$ and $0.6 \%$ for Dp and Ds, respectively $(\mathrm{p}<0.05)$. Nevertheless, PEF daily variability did show a significant decrease $(\mathrm{p}<0.05)$ at 12 months when combining data of both trials (Fig. 3) as well as, when comparing to pretreatment values. On the other hand, skin reactivity to each allergen did show a remarked decrease. The Ch10 value decreased significantly ( $\mathrm{p}<0.05)$, both, in comparison with the onset and with respect to the placebo group, even more significant at 12 months (Fig 4). Moreover, the treatment with Dp induced, not only the reduction of sensitivity to $\mathrm{Dp}$, but also to Ds and vice versa. In contrast, skin reactivity towards the mite Blomiatropicalis did not changed. Combining the results of both trials, most patients $(52 \%)$ completely abolished the skin reactivity to the causative allergen (i.e. they showed no wheals or below $3 \mathrm{~mm}$ diameter) or decreased it remarkably in more of 1 logarithm of Ch10 (78\% of patients), i.e, at least a 10 -fold increase in the allergen threshold.

According to the Overall Clinical Improvement (OCI) variable, $70 \%$ of the patients in the Active group were reported as "better" relative to the treatment onset, both for Dp and Ds. Overall, OR of improvement was 28.8 (95\%CI: 7.4 to 111.8). The decrease of skin reactivity to the administered allergens (Dp or Ds) correlated significantly with the change in primary clinical outcome: the SM score $(r=0.514 ; \mathrm{p}<0.05)$. Furthermore, there was a significant correlation $(\mathrm{r}=0.462 ; \mathrm{p}<0.05)$ between the decrease in daily variability of PEF and change of skin reactivity.

During this study 1638 injections were given, 819 in the active 
Table 1. Dosing schedule of immunotherapy.

\begin{tabular}{|c|c|c|c|}
\hline Week & Concentration (BU/mL) & Volume (mL) & Dose (BU) \\
\hline I & 20 & 0.2 & 4 \\
\hline 2 & 20 & 0.5 & 10 \\
\hline 3 & 20 & 1 & 20 \\
\hline 4 & 200 & 0.2 & 40 \\
\hline 5 & 200 & 0.5 & 100 \\
\hline 6 & 200 & 1 & 200 \\
\hline 7 & 2000 & 0.2 & 400 \\
\hline 8 & 2000 & 0.4 & 800 \\
\hline 9 & 2000 & 0.6 & 1200 \\
\hline 10 & 2000 & 0.8 & 1600 \\
\hline II & 20000 & 0.1 & 2000 \\
\hline 12 & 20000 & 0.2 & 2000 \\
\hline 13 & 20000 & 0.3 & 6000 \\
\hline 271052 & 20000 & 0.3 & 6000 \\
\hline
\end{tabular}

Table 2. Demographic and clinical characteristics of included patients (baseline levels).

\begin{tabular}{|c|c|c|c|}
\hline & $\begin{array}{l}\text { Active Group } \\
\qquad(n=10)\end{array}$ & $\begin{array}{l}\text { Placebo Group } \\
\qquad(n=20)\end{array}$ & $\begin{array}{c}\mathbf{P} \\
\text { Mann-Whitney U Test; } \\
* \text { T-Test; } \nmid \varkappa^{2} \text { test }\end{array}$ \\
\hline \multicolumn{4}{|c|}{ Sex: (Male/Female) } \\
\hline For DP & $13 / 7$ & $9 / 11$ & $0.3 \dagger$ \\
\hline For DS & $10 / 10$ & $7 / 13$ & $0.5 \dagger$ \\
\hline \multicolumn{4}{|c|}{ Age in Years: Median (Range) } \\
\hline For DP & $32(19-44)$ & $37(18-43)$ & $0.7 *$ \\
\hline For DS & $29(23-40)$ & $33(17-42)$ & $0.8^{*}$ \\
\hline \multicolumn{4}{|c|}{ Height in cm: Mediam (Range) } \\
\hline For DP & $168(157-176)$ & $165(154-175)$ & $0.83^{*}$ \\
\hline For DS & $169.5(156.5-177)$ & $164.5(151.5-177)$ & $0.81 *$ \\
\hline \multicolumn{4}{|c|}{ Weight in Kg: Median (Range) } \\
\hline For DP & $77.0(60.8-80.7)$ & $78.0(63.5-90.6)$ & $0.69 *$ \\
\hline For DS & $73.6(59.5-88.1)$ & $74.5(63.5-89)$ & $0.87^{*}$ \\
\hline \multicolumn{4}{|c|}{ Peak Expiratory Flow PEF: Median (Range) } \\
\hline For DP & $81.1(78.8-84.7)$ & $82.3(80.8-84.2)$ & $0.68^{*}$ \\
\hline For DS & $81.2(76.4-89.1)$ & $87.7(80.5-84.5)$ & $0.66^{*}$ \\
\hline \multicolumn{4}{|c|}{ Peak Expiratory Flow Variability: Median (Range) } \\
\hline For DP & $25.4(19.5-27.1)$ & $25.0(21.7-26 . S)$ & $0.48^{*}$ \\
\hline For DS & $29.7(25.1-35.1)$ & $28.1(26.6-31.9)$ & $0.71 *$ \\
\hline \multicolumn{4}{|c|}{ Penistent Allergic Asthma: Mild/Moderate filloderate } \\
\hline For DP & $13 / 7$ & $3 / 17$ & $0.20 \dagger$ \\
\hline For DS & $11 / 9$ & $15 / 5$ & $0.29+$ \\
\hline
\end{tabular}

group. All patients in the active groupreached the expected maintenance dose of $6000 \mathrm{BU}$ and the planned treatment duration of 12 months.All adverse events were classified as local immediate allergic reactions. There were nine and ten reactions for Dp and Ds, respectively. All these events occurred with the build-up dose ( $0.5 \mathrm{~mL}$ of vial number $2,100 \mathrm{BU})$. The observed local reactions consisted of pruritus and wheals smaller than $5 \mathrm{~cm}$ at the injection site and were considered mild. No systemic reactions were reported.

In the Dp trial, the frequency of patients with local adverse reactions in the Active group was $30 \%$ (6 out of 20). Three patients showed repeated reactions at two administrations. Only one patient had a nonspecific local reaction (not associated to the product), a mild pain and cramp sensation at the site of injection, which disappeared spontaneously. Therefore, the frequency 
Figure 1. Flow diagram of the progress through the phases of parallel randomized clinical trials.

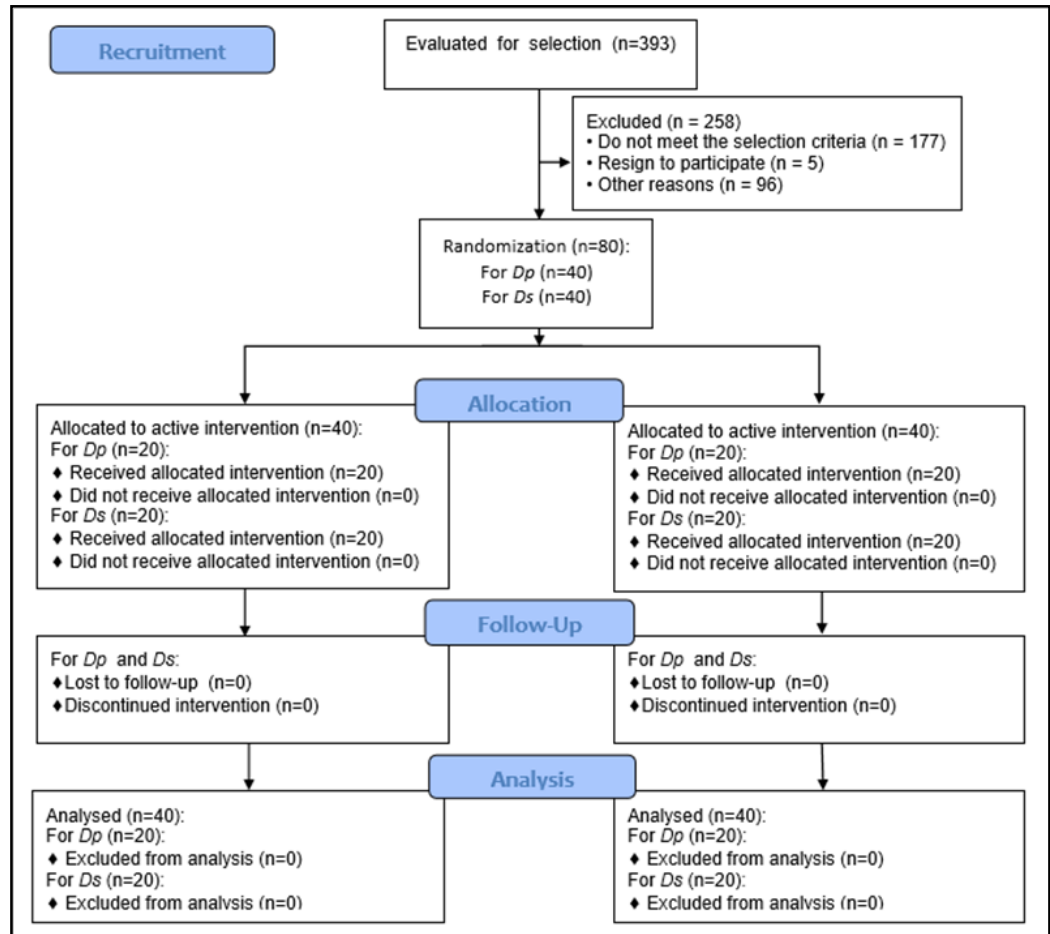

Figure 2. Symptom-Medication score (median values) in active and placebo groups during the AIT with $D$. pteronyssinus vaccine (DP) or D. siboney (DS). Vertical bars indicate $95 \%$ CI.

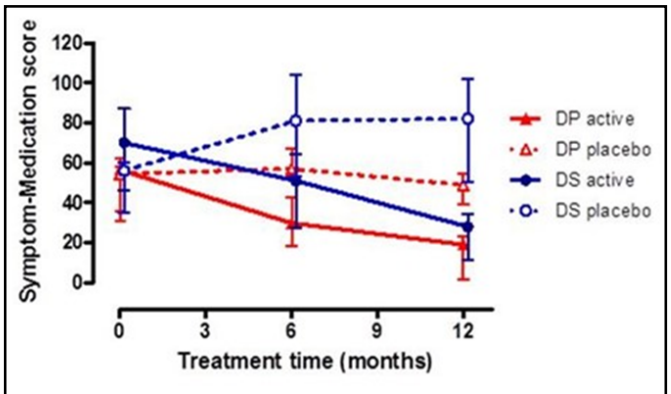

Figure 3. Daily variability of the Peak Expiratory Flow (PEFV) during treatment. Chart shows combined data of both clinical trials, for the active and placebo groups (median value and $95 \%$ confidence interval of the median). The difference was significant at 12 months $(\mathrm{p}=0.03$, Wilconxon).

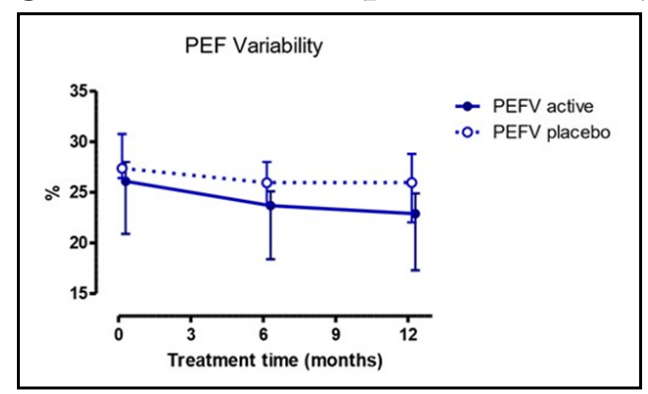

of patients with reactions attributable to the product was $25 \%(5$ out of 20). The frequency of adverse reactions with respect to the number of injections administered was $2.2 \%$ in the Active group versus $0.2 \%$ with Placebo. Similarly, in the Ds trial, the frequency of patients with local adverse reactions in the Active group was 30 $\%$. Four patients suffered from repeated reactions at two distinct administrations. The frequency of patients with reactions linked to the product was $25 \%$. Finally, the frequency of adverse reactions with respect to the amount of injections administered was $2.5 \%$ in the Active group versus $0.5 \%$ with Placebo.

\section{Discussion}

This work encompasses two clinical trials of allergen immunotherapy using House Dust Mite extracts of the closely related species Dermatophagoides pteronyssinus and Dermatophagoides siboney. The last species is prevalent in Cuba and the Caribbean and could be considered a tropical evolutionary descent of D. farinae. This work describes the first double-blind placebo controlled trial for a D. siboney allergen extract. Both allergen products Dp and Ds were standardized sharing the same potency. The dosage schedule, as well as, the study methodology, clinical site and research team coincided. The study results were highly 
Figure 4. Skin reactivity, as measured by Ch10 value to allergen extracts of D. pteronyssinus (Dp), D. siboney (Ds) and Blomiatropicalis (Bt) showing both allergen-specific effects towards the vaccine antigens (Dp or Ds) and the cross-desensitizing effect between Dp and Ds and lack of it towards Bt. (A: Subcutaneous IT using a D. pteronyssinus vaccine; B: using a $D$. siboney vaccine).

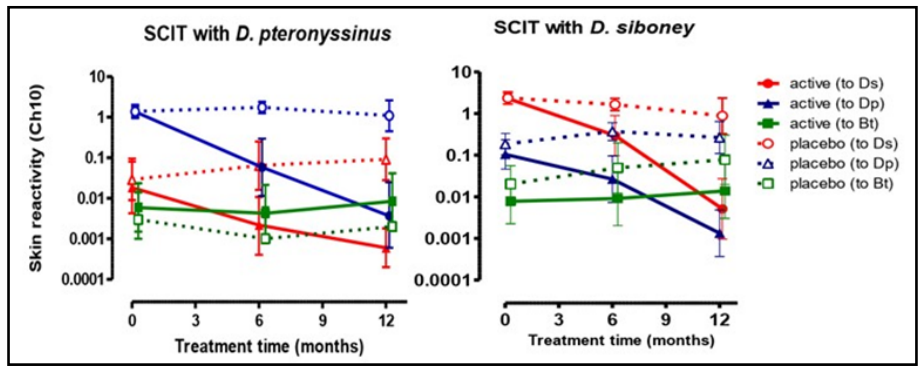

satisfactory in terms of clinical improvement and, particularly, of the decrease of allergen specific skin reactivity, as well as, of the cross-desensitization effect between Ds and Dp. Notably, the AIT with Ds performed as well, or may be slightly better, than the well-studied Dp. The decrease of symptoms was of a similar magnitude that the Standard Mean Difference (SMD) reported in a well-known meta-analysis of subcutaneous immunotherapy using HDM allergens of $\mathrm{D}$. pteronyssinus and D. farinae species (SMD for symptoms: -0.85 (Dp) to -1.30 (Ds) versus -1.13 in the Abramson metaanalysis); whereas the effect on medication was apparently higher here: SMD for medication: -0.82 (Dp) to -1.26 (Ds) versus -0.51 in the Abramson review.21 Nevertheless, it should be noted that medication scores are far to be homogeneous between different authors.[22]

The results regarding PEF and its variability coincide with that reported by Abramson in the sense that IT induces small or none effect on the respiratory function; however, in this case the effect on PEF variability, although small, was significant.[21] In contrast, allergen specific skin reactivity decreased dramatically. The magnitude of this effect, which by the Ch10 definition can be translated into a 277 -fold increase of the allergen threshold able to elicit a positive skin reaction, was higher than the reported in most publications. $[17,18,20,22]$ It is notorious that Ds immunotherapy induced not only reduction of skin reactivity to Ds extract; but also to Dp and vice versa, which was expected due to the high cross-reactivity between both Dermatophagoides species, aspreviously described.[35] As far as we know, this is the first factual report of this cross-effect during IT between Dp and Ds obtained in a controlled trial, since Ds is not found outside of the Caribbean region. [11, 12] As expected, this cross-desensitization effect was absent for $\mathrm{Bt}$, since this species has only very limited cross-reactivity to Dermatophagoides.[2] In full agreement with this finding, a recent work has described the opposite, i.e, the lack of cross-desensitization effect of AIT using Bt extracts towards Dp or Ds.[36]

The question of correlation between change of allergen skin reactivity and clinical improvement has been controversial.[37-39] Confirming this correlation can be relevant for the proposed use of skin test as surrogates markers of clinical efficacy during AIT, a point that has been recently raised by several authors. $[40,41]$ This study has, indeed, shown a significant correlation between skin reactivity and SM score, which supports the use of carefully measured skin reactivity by means of Ch10 (relative to Histamine standard) as a marker of efficacy.[42] Lack of relevant correlations in other studies could be due to the inaccuracy of the used SPT methodology and poorer performance, or the use of absolute variable values and not the shift occurred during treatment period (i.e. the differences between final and initial values). Moreover, the Ch10 parameter eliminates the non-specific effect related to Histamine reactivity, thus raising accuracy. In addition, achievement of significant correlation values can be benefitted by the large effect noticed in this work for both variables: SM and Ch10. Skin tests have the advantages of simplicity and relative safety over other gold-standard diagnostic procedures, such as bronchial provocation tests, whereas a strong association has been reported between boths.[39]

Although subcutaneous AIT has been widely used and acknowledged as an effective treatment, demonstrating clear benefits in reducing allergic symptoms, safety has been a major concern. In fact, the main disadvantage of this type of treatment is the occurrence of adverse events, some of them with a systemic character, which can be very inconvenient for the patient and, even, pose a life-threatening risk. In this study, the frequency of adverse reactions attributable to the product was comparable to that reported internationally, both with respect to the total number of injections and to the number of patients. [17, 18, 20, 22]

However, here all reactions were local; noteworthy, no systemic reactions were observed in this study. It has been reported that systemic allergic reactions during AIT occurs in approximately 0.1 to $0.2 \%$ of injections and roughly $2 \%$ to $5 \%$ of patients. $[18,32$, $33,43-45]$ However, the number of patients in this study may be too small to support conclusions on this issue. Factors favoring minimization of systemic reactions in this study could be: the accurate standardization of the allergen extracts, proper patient selection and careful clinical examination prior to the injection administration, as well as, surveillance during the injection procedure. $[17,18,20,22,44]$

The current study was performed in adults with a range of ages from 17 to 45 years in a population sample representative of Cuban adult allergic asthmatic population. Asthma is the most relevant allergic disease in terms of social and healthcare impact worldwide; nevertheless, HDM sensitization is also a common cause for allergic rhinitis. In agreement with this fact, rhinitis was a frequent comorbidity in asthmatic patients recruited to these clinical trials. The design of these trials addressed only asthma endpoints, therefore, no data was collected regarding the evolution of rhinitis symptoms, although it is likely that the same also improved during the treatment. More studies should be conducted to expand and confirm these results, particularly in children. 
Summarizing, AIT with D. pteronyssinus and, remarkably, D. siboney standardized allergen extracts, was effective and safe for the control and amelioration of the allergic asthma in the Cuban population commonly exposed to these allergens. This is the first published report worldwide of AIT using D. siboney allergens. Subcutaneous AIT should be applied in specialized allergy/immunology services, taking into account internationally recommended safety standards.

\section{List of abbreviations}

AIT: Allergen-Specific Immunotherapy

Dp: Dermatophagoides Pteronyssinus

Ds: Dermatophagoides Siboney

SCIT: Subcutaneous Immunotherapy

BU: Biological Units

PEF: Peak expiratory Flow

HDM: House Dust Mites

Bt: Blomiatropicalis

CECMED: Cuban Regulatory Authority

GINA: Global InitiativeforAsthma

BIOCEN: Centro Nacional de Biopreparados

SM: Symptom and Medication

PEF: Peak Expiratory Flow

OCI: Overall Clinical Improvement

SMD: Standard Mean Difference

PEFV: Daily variability of the Peak Expiratory Flow

\section{Declarations}

\section{Ethics Approval and Consent to Participate}

The study was conducted following the ethical principles contained in the Declaration of Helsinki (64th WMA General Assembly, Fortaleza, Brazil, October 2013. Subjects were asked for their written informed consent to participate in the study. The study was approved by the Ethics Committee of the "Calixto García" University Hospitaland was approved by the Cuban medicine regulatory authority (CECMED).

\section{Consent for publication}

All authors gave its written consent for publication.

\section{Availability of data and materials}

Please contact author for primary data requests.

\section{Conflict interests}

The authors have no conflicts of interest.

\section{Funding}

The research work was funded by the Cuban government: Ministry of Science, Technology and Environment and Ministry of Public Health. Forum SYD and Swedish International Development Cooperation Agency contributed to partially funding this work at the early stages.

\section{Authors' contributions}

Contributions of authors to the manuscript:

Raúl Lázaro Castro-Almarales (AD, AE, CI, DE, TM).

Mercedes Ronquillo-Díaz (AD, AE, CI, DE, IE).

Mirta Álvarez-Castelló (AD, AE, CI, DE, IE)

José Rodríguez-Canosa (AD, DE, CI, IE)

Mayda González-León (AD, DE, CI, IE)

Irene Enríquez-Domínguez (AD, DE, CI, IE)

Bárbara Ivonne Navarro-Viltre (AD, DE, CI, IE)

Mayteé Mateo-Morejón (AD, DE, IE)

Yunia Oliva-Díaz (AD, DE, IE)

Wendy Ramírez-González(AD, DE, IE)

Alexis Labrada-Rosado, PhD (AD, AE, CI, DE)

AD: Acquisition of data, or analysis and interpretation of data. AE: Performed the statistical analysis.

CI: Have been involved in drafting the manuscript or revising it critically for important intellectual content.

DE: Conceived of the study, and participated in its design and performed of study.

IE: carried out the immunoassays and skin tests.

TM: Trial monitoring

\section{Acknowledgements}

To Professor StenDreborg for its valuable training and advice in Skin Tests and Immunotherapy, and to Forum SYD and Swedish International Development Cooperation Agency.

\section{References}

[1]. Pawankar R, Canonica GW, Holgate ST, Lockey RF. WAO White Book on Allergy 2011-2012.

[2]. Caraballo L, Zakzuk J, Lee BW, Acevedo N, Soh JY, Sánchez-Borges M, et al. Particularities of allergy in the Tropics. World Allergy Organ J. 2016 Jun 27;9:20. Pubmed PMID: 27386040.

[3]. Mallol J, Crane J, von Mutius E, Odhiambo J, Keil U, Stewart A. ISAAC Phase Three Study Group. The International Study of Asthma and Allergies in Childhood (ISAAC) Phase Three: a global synthesis. Allergol Immunopathol (Madr). 2013 Mar-Apr;41(2):73-85. Pubmed PMID: 22771150.

[4]. Marks G, Pearce N, Strachan D, Asher I. The Global Asthma Report 2014.

[5]. Díaz-Rodríguez A. Allergology in Cuba. General overview and future perspectives.Junior Member News 2013.

[6]. Mallol J, Solé D, Baeza-Bacab M, Aguirre-Camposano V, Soto-Quiros M, Baena-Cagnani C. Latin American ISAAC Group. Regional variation in asthma symptom prevalence in Latin American children. J Asthma. 2010 Aug;47(6):644-50. Pubmed PMID: 20642377.

[7]. Diaz Rodriguez A, Rosado AL, Almarales RL, Castelló MÁ. Current status and future perspectives of immunotherapy in Latin America and Cuba. World Allergy Organ J. 2014 Nov 12;7(1):28. Pubmed PMID: 25829980.

[8]. Fabré Ortiz D, Varona Pérez P, Suárez Medina R. Prevalencia de asma en adolescentes cubanos por diferentes criterios clínicos [Prevalence of asthma in Cuban adolescents by different clinical criteria]. Rev Alerg Mex. 2005 May-Jun;52(3):132-7. Spanish. Pubmed PMID: 16158787.

[9]. 9. de Salud AE. Dirección Nacional de Registros Médicos y Estadísticas de Salud. La Habana: Ministerio de Salud Pública. 2011.

[10]. Varona Pérez P, García Roche R, Díaz-Perera Fernández G, María Gálvez A, Bonet Gorbea M, González C, Van Der Stuyft P. Uso de servicios de salud y gastos de bolsillo por asma en niños de 5 a 14 ańos de edad: Ciudad de La Habana, 2002. Revista Cubana de Higiene y Epidemiología. 2005;43(3):3841.11.

[11]. van Hage-Hamsten M. Dermatophagoides siboney and Blomia tropicalis--dust mites of subtropical and tropical areas. Clin Exp Allergy. 1995 Oct;25(10):905-7. Pubmed PMID: 8556557.

[12]. Fernández-Duro BI, Cuervo-Pineda N, Rodríguez-Alvízar JA, Celio-Murillo R, Juárez-Anaya D, Pérez-Ortiz TM. Identificación de la fauna de ácaros del 
polvo doméstico en colchones de pacientes alérgicos de seis estados mexicanos [Identification of house dust mite fauna from allergic patients' mattress in six Mexican states]. Rev Alerg Mex. 2013 Jul-Sep;60(3):87-92. Spanish. Pubmed PMID: 24274602

[13]. Ferrandiz R, Casas R, Dreborg S. Sensitization to Dermatophagoides siboney, Blomia tropicalis, and other domestic mites in asthmatic patients. Allergy. 1996 Jul;51(7):501-5.

[14]. Cuervo N, Dusbabek F, de la Cruz J, Abreu R. Los ácaros (acarina: Pyroglyphidae, Cheyleitidae, Saproglyphidae y Glycyphagidae) de los polvos domésticos en Cuba [Acarids (Acarina: Pyroglyphidae, Cheyletidae, Saproglyphidae and Glycyphagidae) of house dust in Cuba]. Rev Cubana Med Trop. 1983 Feb-Apr;35(1):83-103. Spanish. PMID: 6351195.

[15]. Astro Almarales RL, Mateo Morejón M, Naranjo Robalino RM, Navarro Viltre BI, Alvarez Castelló M, Ronquillo Díaz M, García Gómez I, et al. Correlation between skin tests to Dermatophagoides pteronyssinus, Dermatophagoides siboney and Blomia tropicalis in Cuban asthmatics. Allergol Immunopathol (Madr). 2006 Jan-Feb;34(1):23-6. Pubmed PMID: $16540067 .$.

[16]. Ferrándiz R, Casas R, Dreborg S, Einarsson R, Fernández B. Crossreactivity between Dermatophagoides siboney and other house dust mite allergens in sensitized asthmatic patients. Clin Exp Allergy. 1995 Oct;25(10):929-34. Pubmed PMID: 8556563.

[17]. Bousquet J, Lockey R, Malling HJ. Allergen immunotherapy: therapeutic vaccines for allergic diseases A WHO position paper. Journal of Allergy and Clinical Immunology. 1998 Oct 1;102(4):558-62.

[18]. Cox L, Nelson H, Lockey R, Calabria C, Chacko T, Finegold I, Nelson M, et al. Allergen immunotherapy: a practice parameter third update. J Allergy Clin Immunol. 2011 Jan;127(1):S1-55. Pubmed PMID: 21122901.

[19]. Akdis CA, Akdis M: Mechanisms of allergen-specific immunotherapy. J Allergy ClinImmunol 2011, 127, 1:18-27.

[20]. Burks AW, Calderon MA, Casale T, Cox L, Demoly P, Jutel M, Nelson H, et al. Update on allergy immunotherapy: American Academy of Allergy, Asthma \& Immunology/European Academy of Allergy and Clinical Immunology/PRACTALL consensus report. J Allergy Clin Immunol. 2013 May;131(5):1288-96.e3. Pubmed PMID: 23498595.

[21]. Abramson MJ, Puy RM, Weiner JM. Injection allergen immunotherapy for asthma. Cochrane Database Syst Rev. 2010 Aug 4;(8):CD001186. Pubmed PMID: 20687065.

[22]. Jutel M, Agache I, Bonini S, Burks AW, Calderon M, Canonica W, Cox L, et al. International Consensus On (ICON). Allergy Immunotherapy (AIT). J Allergy ClinImmunol. 2015;136, 3:556-68.

[23]. Jiménez G, Pascual MA, Fors M, Cobas J, Torres A, Cachimaille Y, Rodríguez J et al. The Cuban Public Registry of Clinical Trials: primary registry of World Health Organization. J Evid Based Med. 2011;4(3):161-4. Pubmed PMID: 21894615.

[24]. Nordic Council on Medicines. Registration of allergen preparations: Nordic Guidelines. NLN Publication. 1989;23:1-34.

[25]. Labrada Rosado A. Desarrollo a ciclo completo de las primeras vacunas estandarizadas de alergenos de ácaros para la inmunoterapia del asma en Cuba. Tesis de Doctor en Ciencias de la Salud. Instituto Superior de Ciencias Médicas de La Habana, 2009. Editorial Universitaria, La Habana 2012. ISBN 978-959-16-1711-8 - 193.

[26]. Koshak EA. Classification of asthma according to revised 2006 GINA: Evolution from severity to control. Annals of thoracic medicine. 2007 Apr;2(2):45.

[27]. Malling HJ. Criteria for clinical efficacy--readout and monitoring of clinical studies. Arbeiten aus dem Paul-ehrlich-institut (Bundesamt fur Sera und Impfstoffe) zu Frankfurt aM. 2003 Jan 1(94):119-23.

[28]. Canonica GW, Baena-Cagnani CE, Bousquet J, Bousquet PJ, Lockey RF, Malling HJ, Passalacqua G, et al. Recommendations for standardization of clinical trials with Allergen Specific Immunotherapy for respiratory allergy. A statement of a World Allergy Organization (WAO) taskforce. Allergy. 2007 Mar;62(3):317-24. Pubmed PMID: 17298350.

[29]. Higgins JPT, Green S. Cochrane Handbook for Systematic Reviews of Interventions v4.2.6 Sept 2006.
[30]. Dreborg S. Skin testing. The safety of skin tests and the information obtained from using different methods and concentrations of allergen. Allergy. 1993 Oct;48(7):473-5. Pubmed PMID: 8238806

[31]. Lebowitz MD. The use of peak expiratory flow rate measurements in respiratory disease. Pediatric pulmonology. 1991;11(2):166-74.

[32]. Quackenboss JJ, Lebowitz MD, Krzyzanowski M. The normal range of diurnal changes in peak expiratory flow rates. Relationship to symptoms and respiratory disease. Am Rev Respir Dis. 1991 Feb;143(2):323-30. Pubmed PMID: 1990947.

[33]. Cox L, Larenas-Linnemann D, Lockey RF, Passalacqua G. Speaking the same language: The World Allergy Organization Subcutaneous Immunotherapy Systemic Reaction Grading System. J Allergy Clin Immunol. 2010 Mar;125(3):569-74, 574.e1-574.e7. Pubmed PMID: 20144472.

[34]. Cox LS, Sanchez-Borges M, Lockey RF. World Allergy Organization Systemic Allergic Reaction Grading System: Is a Modification Needed? J Allergy Clin Immunol Pract. 2017 Jan-Feb;5(1):58-62.e5. Pubmed PMID: 28065342.

[35]. Ferrándiz R, Casas R, Dreborg S. Cross-reactivity between Dermatophagoides siboney and other domestic mites. II. Analysis of individual crossreacting allergens after SDS-PAGE and Western blotting inhibition. Int Arch Allergy Immunol. 1998 Jul;116(3):206-14. Pubmed PMID: 9693268.

[36]. Castro-Almarales RL, Ronquillo-Díaz M, Álvarez-Castelló M, RodríguezCanosa J, González-León M, Enríquez-Domínguez I, Navarro-Viltre BI, et al. Subcutaneous allergen immunotherapy for asthma: A randomized, double-blind, placebo-controlled study with a standardized Blomia tropicalis vaccine. World Allergy Organ J. 2020 Apr 10;13(4):100098. Pubmed PMID: 32308779.

[37]. Calderon MA, Casale TB, Nelson HS, Demoly P. An evidence-based analysis of house dust mite allergen immunotherapy: a call for more rigorous clinical studies. J Allergy Clin Immunol. 2013 Dec;132(6):1322-36. Pubmed PMID: 24139829.

[38]. Lee E, Kim MJ, Yang SI, Yu J, Hong SJ. Comparison of short-term effects between subcutaneous and sublingual immunotherapies in children with house dust mite-sensitized allergic rhinitis and asthma. Allergy, Asthma \& Respiratory Disease. 2015 May 1;3(3):180-6.

[39]. Son JY, Jung MH, Koh KW, Park EK, Heo JH, Choi GS, Kim HK. Changes in skin reactivity and associated factors in patients sensitized to house dust mites after 1 year of allergen-specific immunotherapy. Asia Pac Allergy. 2017 Apr;7(2):82-91. Pubmed PMID: 28487839.

[40]. Cox LS. Sublingual Immunotherapy for Allergic Rhinitis: Is 2-Year Treatment Sufficient for Long-term Benefit? JAMA. 2017 Feb 14;317(6):591593. Pubmed PMID: 28196239..

[41]. Scadding GW, Calderon MA, Shamji MH, Eifan AO, Penagos M, Dumitru F, Sever ML, et al. Immune Tolerance Network GRASS Study Team. Effect of 2 Years of Treatment With Sublingual Grass Pollen Immunotherapy on Nasal Response to Allergen Challenge at 3 Years Among Patients With Moderate to Severe Seasonal Allergic Rhinitis: The GRASS Randomized Clinical Trial. JAMA. 2017 Feb 14;317(6):615-625. Pubmed PMID: 28196255.

[42]. Dreborg S. Allergen skin prick test should be adjusted by the histamine reactivity. Int Arch Allergy Immunol. 2015;166(1):77-80. Pubmed PMID: 25765942.

[43]. Epstein TG, Liss GM, Murphy-Berendts K, Bernstein DI. AAAAI/ACAAI surveillance study of subcutaneous immunotherapy, years 2008-2012: an update on fatal and nonfatal systemic allergic reactions. J Allergy Clin Immunol Pract. 2014 Mar-Apr;2(2):161-7. Pubmed PMID: 24607043.

[44]. Kowalski ML, Ansotegui I, Aberer W, Al-Ahmad M, Akdis M, Ballmer-Weber BK, Beyer K, et al. Risk and safety requirements for diagnostic and therapeutic procedures in allergology: World Allergy Organization Statement. World Allergy Organ J. 2016 Oct 12;9(1):33. Pubmed PMID: 27777642.

[45]. Epstein TG, Liss GM, Murphy-Berendts K, Bernstein DI. Risk factors for fatal and nonfatal reactions to subcutaneous immunotherapy: National surveillance study on allergen immunotherapy (2008-2013). Ann Allergy Asthma Immunol. 2016 Apr;116(4):354-359.e2. Pubmed PMID: 26948485. 